\title{
Experimental Study on Picking Unit Parameters of Brush-rolling Cotton Harvester
}

\author{
Jinkun Pan ${ }^{1, *}$, Jianning Yuan ${ }^{1}$, Lei Shi ${ }^{2}$, Yutong Zhang ${ }^{2}$, and Zixian Guo ${ }^{1}$ \\ ${ }^{1}$ School of Mechanical Engineering, Nanjing Institute of Technology, Nanjing, 211167, China \\ ${ }^{2}$ Nanjing Research Institute of Agricultural Mechanization, Ministry of Agriculture and Rural Affairs, Nanjing, 210014, China
}

\begin{abstract}
In order to find the optimal combination of the picking unit parameters of the brush-rolling cotton harvester, the parameters optimization experiment were carried out. Taking the rotary speed of brush roller, the working velocity, and the number of brush plates as the experimental factors, the collect rate and the loss rate of struck cotton as the performance evaluation indexes, the quadratic regression orthogonal rotational combing design experiment was carried out. The Central Composite Design response surface method was used to establish the regression model of experimental factors and evaluation indexes, and analyze the influence of each factor on evaluation indexes. Using multi-objective optimization, the optimal parameter combination is as follows: the rotary speed of the brush roller is $350 \mathrm{r} / \mathrm{min}$, the working velocity is $0.5 \mathrm{~m} / \mathrm{s}$, the number of brush plates is 6 rows. After the optimization test, the collect rate is $95.58 \%$, and the loss rate of struck cotton is $1.22 \%$. The field verification test shows that the collect rate of $4 \mathrm{MSG}-3$ brush-rolling cotton harvester is $92.86 \%$, and the loss rate of struck cotton is $1.26 \%$. The relative error between verification test results and parameter optimization value is less than $5 \%$, which verifies the reliability of the regression model. This study provides a theoretical basis for optimizing and improving the picking unit's parameters of the brush-rolling cotton harvester.
\end{abstract}

\section{Introduction}

4MSG-3 brush-rolling cotton harvester is the oppositerow cotton harvester with simple structure, low harvesting cost, simple maintenance procedure, and high harvesting efficiency. Combined with a particular airborne seed cotton pretreatment device, the harvested seed cotton has a low impurity content. It is suitable for popularization in small and medium-sized cotton fields in the Yellow River and Yangtze River basins [1-2]. This paper describes the structure and working principle of the picking unit of the cotton harvester. The main structural parameters of the picking unit are designed and studied. The optimal parameter combination of the picking unit was obtained through the laboratory test of the cotton picker. Through the field test, the optimization results of experimental parameters were evaluated, which provided a theoretical basis for the research on the structure and working parameters of the picking unit of the brush-rolling cotton harvester.

\section{Picking unit Structure and parameters}

\subsection{Structure of brush-rolling cotton harvester}

The 4MSG-3 brush-rolling cotton harvester is generally composed of picking part, conveying part, airborne cleaning part, seed cotton collection part and power system, as shown in Fig. 1.

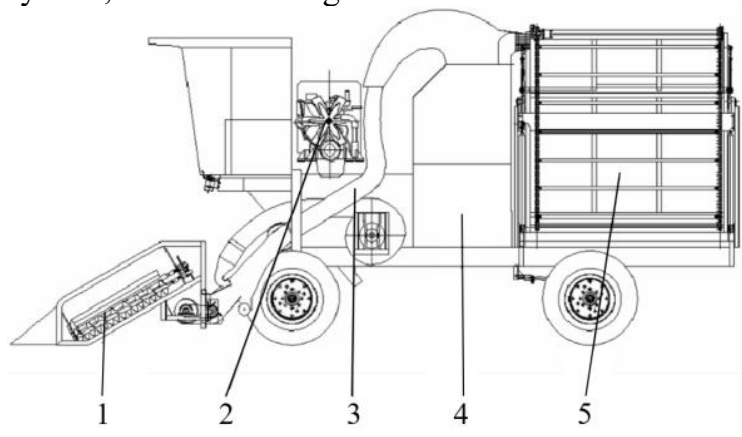

1.Picking head; 2.Engine; 3.Cotton conveyer; 4.Cleaning system; 5.Cotton box

Fig. 1. Structure diagram of brush-rolling cotton harvester.

\subsection{Working principle of picking unit}

The picking head of the brush-rolling cotton harvester has 3 groups of the same picking units, and its structure is shown in Fig. 2. The picking unit consists of a pair of brush rollers arranged in parallel with a certain distance and inclined to the ground at a certain angle. The gap between the brush rollers forms a picking channel, and two sides of the picking channel are equipped with cotton conveying augers.

\footnotetext{
*Corresponding author: msc82915@126.com
} 


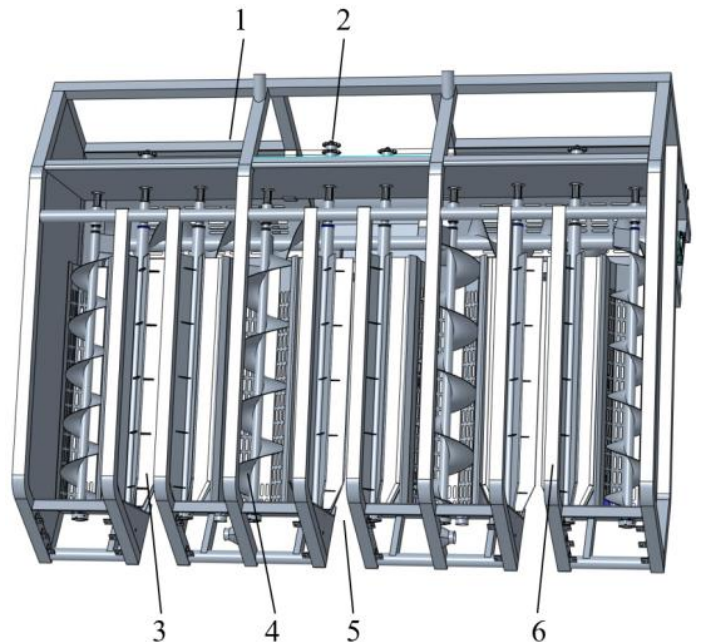

1.Hydraulic motor; 2.Transmission system; 3.Brush roller; 4.Conveying auger; 5.Picking channel; 6.Frame

Fig. 2. Structure diagram of picking head.

During work, the movement and power are input by the hydraulic motor through the transmission system. A pair of brush rollers in the same group rotate at the same speed and in the opposite direction, and the brush plates on the brush roller squeeze and strike the cotton plants entering the picking channel from the bottom up, so that the seed cotton, cotton peach, branches, and leaves are separated from the cotton plant, and under the action of the centrifugal force of the brush plate, it is thrown into the cotton conveying auger on both sides and sent to the discharge port, thus completing the cotton picking process.

\subsection{Main parameters of picking unit}

The picking unit's structural design and working parameters directly affect the quality and efficiency of cotton picking. Therefore, according to the requirements

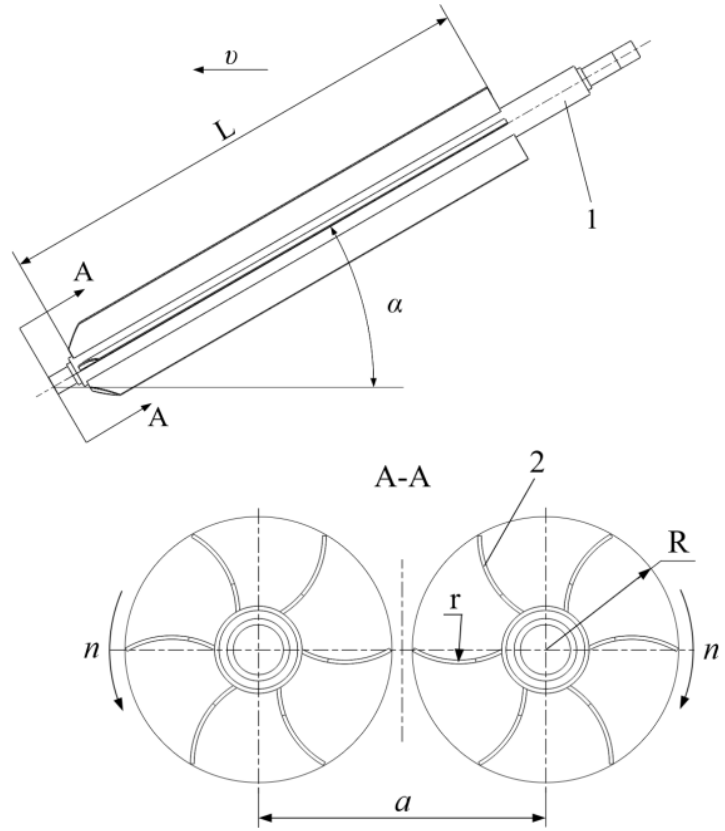

1.Roller shaft; 2.Brush plate

Fig. 3. Schematic diagram of picking unit parameters. of the technical operation regulations of the cotton harvester, taking into account the essential physical characteristics of the machine picking cotton, as well as the planting mode and cotton varieties [3-6], referring to the previous research work, set the structural parameters and working parameters of the picking unit, as shown in Fig. 3 and Table 1.

Table 1. Main parameters of picking unit.

\begin{tabular}{|c|c|}
\hline Parameters & Value \\
\hline Length of brush roller $L / \mathrm{mm}$ & 1100 \\
\hline Radius of brush roller $R / \mathrm{mm}$ & 105 \\
\hline Inclination of brush roller $\alpha /\left(^{\circ}\right)$ & 30 \\
\hline Distance between brush roller $a / \mathrm{mm}$ & 230 \\
\hline Arc radius of brush plate $r / \mathrm{mm}$ & 71 \\
\hline Numbers of brush plates $\mathrm{z} / \mathrm{row}$ & $6,8,10$ \\
\hline Rotary speed of brush roller $n /(\mathrm{r} / \mathrm{min})$ & $300 \sim 340$ \\
\hline Working velocity $v /(\mathrm{m} / \mathrm{s})$ & $0.4 \sim 1$ \\
\hline
\end{tabular}

\section{Materials and methods}

\subsection{Experimental materials and equipment}

Mechanized cotton harvesting is technical and seasonal, and the period suitable for mechanical cotton harvesting is short. In the field, the picking test is susceptible to factors such as site, climate, and mechanical reliability. The structure and parameters of the picking unit are not easy to adjust, test equipment is challenging to install and debug, it is susceptible to interference during work, and test data is inconvenient to collect [7]. In the laboratory environment, the test conditions are controllable, and the test data has a large amount of information. Thus, advanced test methods can be applied, the component structure and parameters are easy to adjust, and the efficiency and accuracy of test research are effectively improved. Therefore, the picking test was arranged in the agricultural machinery station of Wudi County, Binzhou, Shandong, as shown in Fig. 4. The cotton sample variety was 60-3 of the Institute of Cotton Research of CAAS and was planted with $76 \mathrm{~cm}$ equal row spacing. Samples were collected according to Agriculture Industrial Standard NY/T 1133-2006 'Operating quality for cotton picker' [8]. Five samples from each sampling site were randomly selected for testing. The physical parameters of the cotton samples were: the average height of the cotton plant was $75.3 \mathrm{~cm}$, the minimum boll height is $19.3 \mathrm{~cm}$, the moisture content 
of the seed cotton is $8.7 \%$, the rate of boll opening is $94.6 \%$, and the water content is $87.3 \%$. The samples contained different fruit branch morphologies. Each batch of samples completed the picking test within 48 hours of sampling. The test equipment mainly includes 4MSG-3 brush-rolling cotton harvester, DL-17 electronic scale, AT-8 photoelectric tachometer, stopwatch, etc.

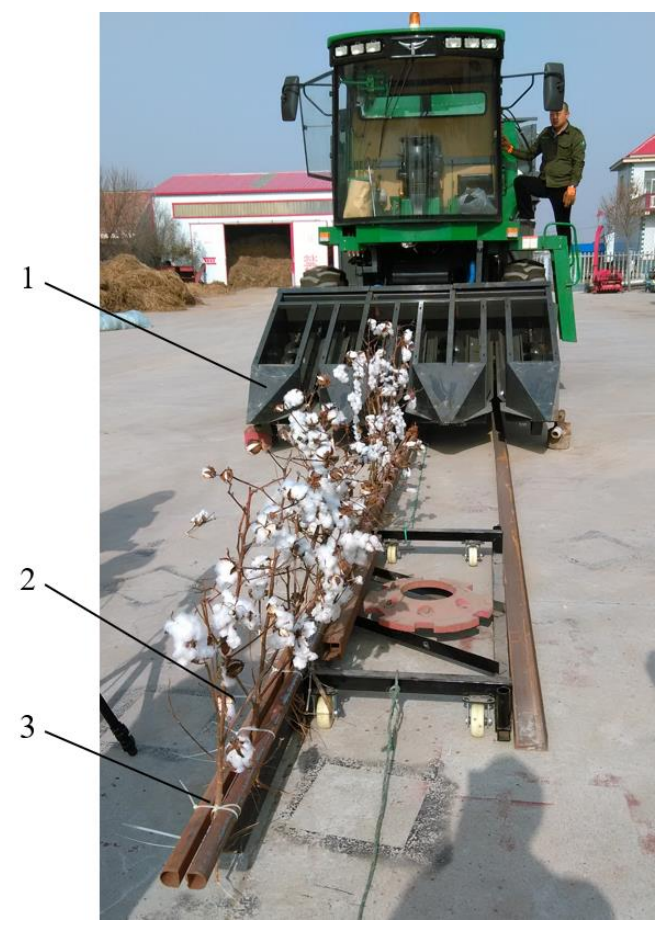

1. Brush-rolling cotton harvester; 2.Cotton plant; 3.Conveyor rail

Fig. 4. Laboratory test site.

\subsection{Test methods}

\subsubsection{Experimental factors and evaluation indexes}

Based on the picking unit structure and parameters, through theoretical analysis and pre-preparation tests, the rotary speed of the brush roller, the working velocity of the cotton harvester, and the number of brush plates were selected as experimental factors. Concerning Agriculture Industrial Standard NY/T 1133-2006, the collect rate and the loss rate of struck cotton were selected as the evaluation indexes of the picking unit.

\subsubsection{Determination of evaluation indexes}

Twenty cotton plants were randomly selected from the samples before the picking test, and the opened cotton bolls were manually picked and weighed, and the average single boll weight was measured. During the test, the cotton plants were fixed on the conveying rail according to the planting distance, and the total number of the opened cotton bolls by the cotton plants on the conveying rail was counted. The total seed cotton mass of the opened cotton bolls was calculated based on the average single boll weight. After harvest, collect stroken cotton, leaved cotton and hitched cotton, remove impurities and weigh them separately. Calculate respectively, according to Equations (1) and (2):

$$
\begin{gathered}
y_{1}=\frac{W-W_{z}-W_{l}-W_{g}}{W} \times 100 \% \\
y_{2}=\frac{W_{z}}{W} \times 100 \%
\end{gathered}
$$

Where, $y_{1}$ is the collect rate $(\%) ; y_{2}$ is the loss rate of struck cotton( $(\%)$; W is the total mass of seed cotton with the opened cotton bolls on the conveying rail, $\mathrm{g}$; $\mathrm{Wz}$ is the mass of stroken cotton, $\mathrm{g}$; $\mathrm{W}_{l}$ is the mass of leaved cotton, $\mathrm{g} ; \mathrm{W}_{\mathrm{g}}$ is the mass of hitched cotton, $\mathrm{g}$.

\subsubsection{Test design}

The quadratic regression orthogonal rotational combing design was adopted to arrange the experiment considering the nonlinearity between the evaluation index and the experimental factors [9-11]. The factor levels are shown in Table 2.

Table 2. Factors and levels of experiment.

\begin{tabular}{|c|c|c|c|}
\hline \multirow{2}{*}{ Level } & \multicolumn{3}{|c|}{ Factors } \\
\cline { 2 - 4 } & $\begin{array}{c}\text { Rotary speed } \\
\text { of brush roller } \\
/(\mathrm{r} / \mathrm{min})\end{array}$ & $\begin{array}{c}\text { Working } \\
\text { velocity } \\
/(\mathrm{m} / \mathrm{s})\end{array}$ & $\begin{array}{c}\text { Number of } \\
\text { brush plates } \\
/ \text { /row }\end{array}$ \\
\hline$-\gamma$ & 286.0 & 0.2 & 4 \\
\hline-1 & 300.0 & 0.4 & 6 \\
\hline 0 & 320.0 & 0.7 & 8 \\
\hline 1 & 340.0 & 1.0 & 10 \\
\hline$\gamma$ & 354.0 & 1.2 & 12 \\
\hline
\end{tabular}

\section{Results and discussion}

\subsection{Test results}

The test was arranged using the Central Composite Design response surface test method [12-14], including 14 non-center points and 6 center points, and a total of 20 groups of experiments were performed [15-18]. Each evaluation index was measured concerning Agriculture Industrial Standard NY/T 1133-2006, and the average of the three replicates was the test result. The test scheme and test results are shown in Table 3. In the table, A, B, and $\mathrm{C}$ are the coded values of the Rotary speed of brush roller, working velocity, and the number of brush plates, respectively. 
Table 3. Experimental program and results.

\begin{tabular}{|c|c|c|c|c|c|}
\hline No. & A & B & $\mathrm{C}$ & $\mathrm{y}_{1} / \%$ & $\mathrm{y}_{2} / \%$ \\
\hline 1 & -1 & -1 & -1 & 95.85 & 0.55 \\
\hline 2 & 1 & -1 & -1 & 96.69 & 0.72 \\
\hline 3 & -1 & 1 & -1 & 90.23 & 0.77 \\
\hline 4 & 1 & 1 & -1 & 91.46 & 2.24 \\
\hline 5 & -1 & -1 & 1 & 87.27 & 0.71 \\
\hline 6 & 1 & -1 & 1 & 92.46 & 1.92 \\
\hline 7 & -1 & 1 & 1 & 87.97 & 3.86 \\
\hline 8 & 1 & 1 & 1 & 95.14 & 5.67 \\
\hline 9 & -1.682 & 0 & 0 & 87.78 & 0.32 \\
\hline 10 & 1.682 & 0 & 0 & 92.87 & 2.85 \\
\hline 11 & 0 & -1.682 & 0 & 95.98 & 0.49 \\
\hline 12 & 0 & 1.682 & 0 & 91.89 & 3.66 \\
\hline 13 & 0 & 0 & -1.682 & 94.75 & 0.74 \\
\hline 14 & 0 & 0 & 1.682 & 94.87 & 2.44 \\
\hline 15 & 0 & 0 & 0 & 92.38 & 1.26 \\
\hline 16 & 0 & 0 & 0 & 93.97 & 0.82 \\
\hline 17 & 0 & 0 & 0 & 94.93 & 1.26 \\
\hline 18 & 0 & 0 & 0 & 93.27 & 1.49 \\
\hline 19 & 0 & 0 & 0 & 94.33 & 1.06 \\
\hline 20 & 0 & 0 & 0 & 94.75 & 0.98 \\
\hline
\end{tabular}

\subsection{Influencing factors of collect rate}

According to the test data in Table 3, Design-Expert 12 was used to analyze the variance analysis of the collect rate [19-20]. According to the Prob $>$ F test, when the $P$ value is less than 0.05 , it is significant, and the non- significant items are excluded. The results are shown in Table 4 .

Table 4. Variance analysis of collect rate.

\begin{tabular}{|c|c|c|c|c|c|}
\hline \multirow{2}{*}{ Source } & \multicolumn{5}{|c|}{ Collect rate } \\
\cline { 2 - 6 } & $\begin{array}{c}\text { Sum of } \\
\text { squares }\end{array}$ & Freedom & $\begin{array}{c}\text { Mean } \\
\text { square }\end{array}$ & F & P \\
\hline Model & 133.80 & 9 & 14.87 & 10.04 & 0.0006 \\
\hline A & 38.70 & 1 & 38.70 & 26.13 & 0.0005 \\
\hline B & 15.08 & 1 & 15.08 & 10.18 & 0.0096 \\
\hline C & 9.17 & 1 & 9.17 & 6.19 & 0.0321 \\
\hline AC & 13.24 & 1 & 13.24 & 8.94 & 0.0136 \\
\hline BC & 25.31 & 1 & 25.31 & 17.09 & 0.0020 \\
\hline A ${ }^{2}$ & 30.45 & 1 & 30.45 & 20.56 & 0.0011 \\
\hline Lack of fit & 10.145 & 5 & 2.03 & 2.17 & 0.2076 \\
\hline Error & 4.67 & 5 & 0.9343 & & \\
\hline As can & 148.61 & 19 & & & \\
\hline & $b e 50 e n$ & $f r o m$ & & \\
\hline
\end{tabular}

As can be seen from Table 4, model $\mathrm{P}<0.01$ is highly significant. The model shows no significant lack of fit, indicating that the influence of various factors on the evaluation index is highly significant. And the model is appropriate, and the regression is effective. The significant influence of each factor on the collect rate is from the big to the small, the rotary speed of brush roller, the working velocity, and the number of the brush plates. For the collect rate $y_{1}$, the regression equation in the form of experimental factor code is:

$$
\begin{array}{r}
y_{1}=93.93+1.68 A-1.05 B-0.8192 C \\
+1.29 A C+1.78 B C-1.45 A^{2}
\end{array}
$$

Fig. 5a shows the surface of interaction between the rotary speed of brush roller A and the number of brush plates $\mathrm{C}$ on the collect rate when the working velocity is at the level of $0(B=0.7 \mathrm{~m} / \mathrm{s})$. As can be seen from Fig. $5 \mathrm{a}$, the collect rate first increases and then decreases with the increase of the rotary speed of the brush roller, but decreases with the increase of the number of brush plates. The surface changed rapidly along the direction $\mathrm{A}$ of the rotary speed of the brush roller, while the change was slower along the direction $\mathrm{C}$ of the number of brush plates. At the corresponding test level, the influence of the rotary speed of brush roller on the collect rate is more significant than that of the number of brush plates. 
Fig. $5 \mathrm{~b}$ shows the surface of interaction between the working velocity $\mathrm{B}$ and the number of brush plates $\mathrm{C}$ on the collect rate when the rotary speed of brush roller is at the level of $0(\mathrm{~A}=320 \mathrm{r} / \mathrm{min})$. As can be seen from Fig. $5 \mathrm{~b}$, the collect rate decreases with the increase of the working velocity, and decreases with the increase of the number of brush plates. The surface changed rapidly along the direction $\mathrm{B}$ of the working velocity, while the change was slower along the direction $\mathrm{C}$ of the number of brush plates. At the corresponding test level, the influence of the working velocity on the collect rate is more significant than that of the number of brush plates.

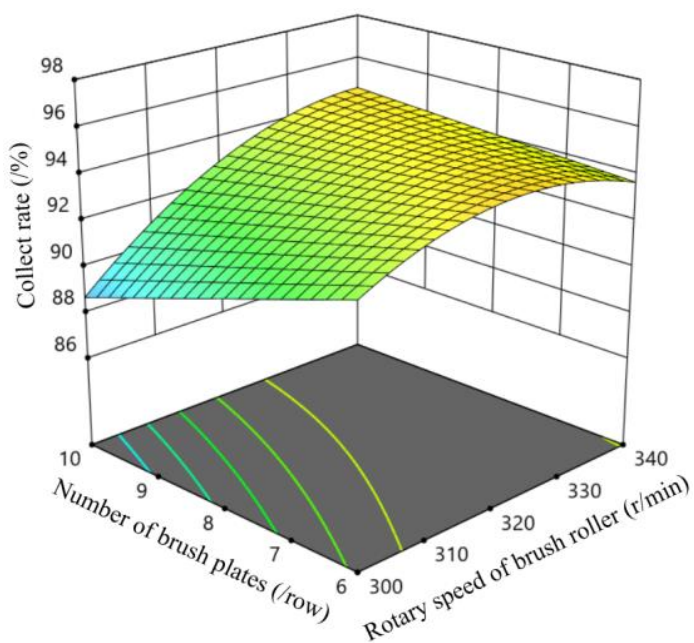

a. Interaction effect between rotary speed of brush roller and number of brush plates

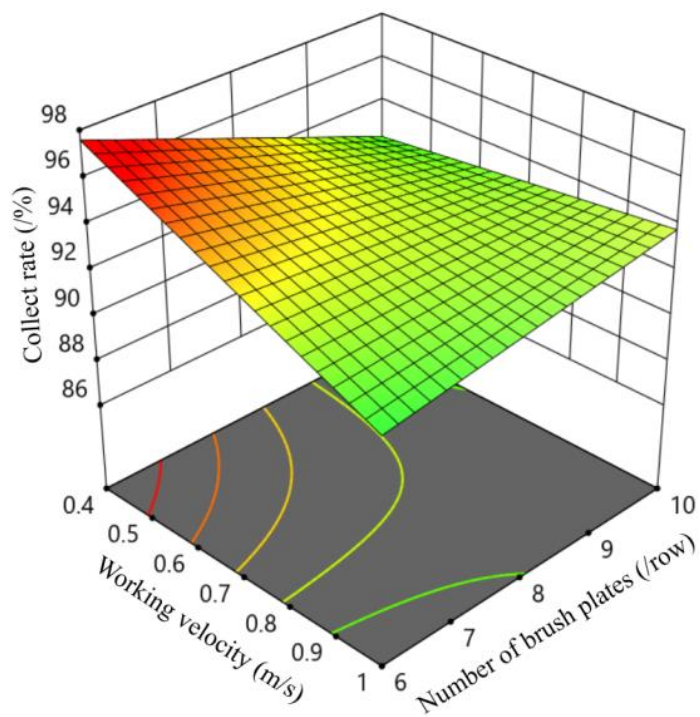

b. Interaction effect between number of brush plates and working velocity

Fig. 5. The influence of interaction on collect rate.

\subsection{Influencing factors of loss rate of struck cotton}

According to the test data in Table 3, Design-Expert 12 was used to analyze the variance analysis of the loss rate of struck cotton [19-20]. According to the Prob> F test, when the $\mathrm{P}$ value is less than 0.05 , it is significant, and the non-significant items are excluded. The results are shown in Table 5 .

Table 5. Variance analysis of loss rate of struck cotton.

\begin{tabular}{|c|c|c|c|c|c|}
\hline \multirow{2}{*}{ Source } & \multicolumn{5}{|c|}{ Loss rate of struck cotton } \\
\cline { 2 - 6 } & $\begin{array}{c}\text { Sum of } \\
\text { square }\end{array}$ & Freedom & $\begin{array}{c}\text { Mean } \\
\text { square }\end{array}$ & F & P \\
\hline Model & 35.50 & 9 & 3.94 & 26.21 & $<0.0001$ \\
\hline A & 5.82 & 1 & 5.82 & 38.66 & $<0.0001$ \\
\hline B & 14.29 & 1 & 14.29 & 95.48 & $<0.0001$ \\
\hline C & 8.44 & 1 & 8.44 & 56.11 & $<0.0001$ \\
\hline BC & 3.33 & 1 & 3.33 & 22.11 & 0.0008 \\
\hline B & 2.12 & 1 & 2.12 & 14.10 & 0.0038 \\
\hline Lack of fit & 1.21 & 5 & 0.2424 & 4.13 & 0.0727 \\
\hline Error & 0.2932 & 5 & 0.0586 & & \\
\hline Total & 37.00 & 19 & & & \\
\hline As can & $6 e$ seen & 19 & & & \\
\hline
\end{tabular}

As can be seen from Table 5, model $\mathrm{P}<0.01$ is highly significant. The model shows no significant lack of fit, indicating that the influence of various factors on the evaluation index is highly significant. And the model is appropriate, and the regression is effective. The significant influence of each factor on the loss rate of struck cotton is from the big to the small, the working velocity, the number of the brush plates, and the rotary speed of brush roller. For the loss rate of struck cotton $y_{2}$, the regression equation in the form of experimental factor code is:

$$
\begin{array}{r}
y_{2}=1.46+0.6528 A+1.02 B+0.7863 C \\
+0.645 B C+0.3455 B^{2}
\end{array}
$$

Fig. 6 shows the surface of interaction between the working velocity $\mathrm{B}$ and the number of brush plates $\mathrm{C}$ on the collect rate when the rotary speed of brush roller is at the level of 0 ( $A=320 \mathrm{r} / \mathrm{min})$.As can be seen from Fig. 6, the loss rate of struck cotton increases with the increase of the working velocity, and increases with the increase of the number of brush plates. The surface changed rapidly along the direction $\mathrm{B}$ of the working velocity, while the change was slower along the direction $\mathrm{C}$ of the number of brush plates. At the corresponding test level, the influence of the working velocity on the loss rate of struck cotton is more significant than that of the number of brush plates. 


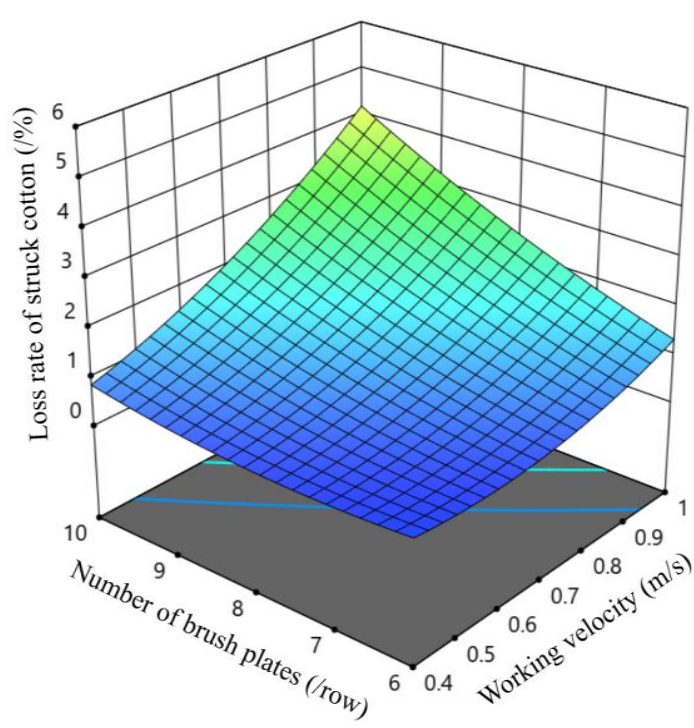

Fig. 6. The influence of interaction on loss rate of struck cotton.

\subsection{Optimal design}

\subsubsection{Parameters optimization analysis}

In order to obtain the best level of experimental factors, the experimental factors are optimized. A mathematical model of parameter optimization is established. The regression equations of the collect rate and the loss rate of struck cotton are analyzed, and the mathematical model of the nonlinear programming is

$$
\begin{aligned}
& \max y_{1} \text { and } \min y_{2} \\
& \text { s.t. }\left\{\begin{array}{l}
286.0 \leq A \leq 354.0 \\
0.2 \leq B \leq 1.2 \\
4.0 \leq C \leq 12.0 \\
90 \leq y_{1}(A, B, C) \leq 98 \\
0 \leq y_{2}(A, B, C) \leq 2.5
\end{array}\right.
\end{aligned}
$$

The unified objective method in the multi-objective optimization method was used for optimization, and the optimization results of the collect rate and the loss rate of struck cotton were: $340 \mathrm{r} / \mathrm{min}$ of the rotary speed of brush roller, $0.5 \mathrm{~m} / \mathrm{s}$ of working velocity, and 6 rows of brush plates. At this time, the collect rate was $95.58 \%$, and the loss rate of struck cotton was $1.22 \%$.

\subsubsection{Optimization parameters test verification}

According to the results of the test optimization parameters, a verification test was performed. The rotary speed of brush roller was $340 \mathrm{r} / \mathrm{min}$, the working velocity was $0.5 \mathrm{~m} / \mathrm{s}$, and the number of brush plates was 6 rows. Considering the difference of indoor and field operation conditions, a verification test was arranged at the field site. Five different test areas of the same field were selected, and each test area was tested three times, and the average of the three replicates was the test result. The field test is shown in Fig. 7, and the verification test results are shown in Table 6. It can be known from Table 6 that the field test evaluation index is slightly lower than the indoor test evaluation index, which is related to the relatively poor field test operation conditions. The relative error between the verification test results and the parameter optimization values is less than $5 \%$, indicating that the optimization model is reasonable. The optimization results can be used as the best parameter combination for the picking unit of the brush-rolling cotton harvester.

Table 6. Results of verification test.

\begin{tabular}{|c|c|c|}
\hline Projects & Collect rate/\% & $\begin{array}{c}\text { Loss rate of } \\
\text { struck cotton/\% }\end{array}$ \\
\hline Optimization value & 95.58 & 1.22 \\
\hline $\begin{array}{c}\text { Verification test } \\
\text { average }\end{array}$ & 92.86 & 1.26 \\
\hline Relative error $\%$ & 2.85 & 3.28 \\
\hline
\end{tabular}

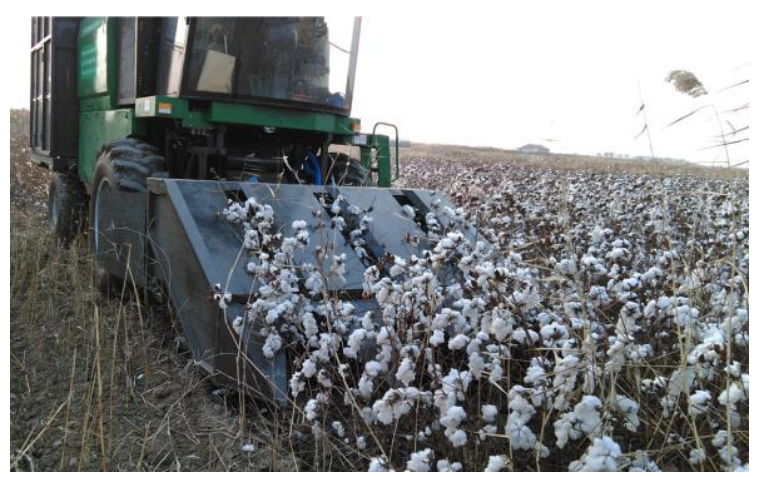

Fig. 7. Field test site.

\section{Conclusion}

1. The experiments were carried out by using quadratic regression orthogonal rotational combing design. A mathematical regression model of the experimental factors and evaluation indexes was established. The influences of the rotary speed of the brush roller, the working velocity, and the number of brush plates on the collect rate and the loss rate of struck cotton were studied.

2. Through the regression equation of collect rate and loss rate of struck cotton, the optimal parameter combination of picking unit of brush-rolling cotton harvester picker obtained as follows: the rotary speed of the brush roller is $340 \mathrm{r} / \mathrm{min}$, the working velocity is 0.5 $\mathrm{m} / \mathrm{s}$, and the brush plate there are 6 rows. As a result of which, the collect rate is $95.58 \%$, and the loss rate of struck cotton is $1.22 \%$.

3. The field verification test showed that the 4MSG-3 brush-rolling cotton harvester had a collect rate of $92.86 \%$ and a loss rate of struck cotton of $1.26 \%$. The relative error between the verification test results and the parameter optimization values was less than $5 \%$, which verified the regression model reliability. 


\section{Acknowledgments}

This research was supported by the Open Project of Key Laboratory of Modern Agricultural Equipment of Ministry of Agriculture (201602003).

\section{References}

1. M. Huang, L. Shi, J. Yuan, Y. Wang, J. China Agric. Mech. 35, 40 (2014)

2. J. Duan, X. Zhang, G. Fan, Y. Wang, J. China Agric. Mech. 35, 62 (2014)

3. Chinese Acad. Agric. Mech. Sci., Handbook of Agricultural Machinery Design (China Agricultural Science and Technology Press, Beijing, 2007)

4. X. Liu, Y. Zhou, X. Yan, J. Mei, X. He, Xinjiang Farm Res. Sci. Tech. 5, 38 (2005)

5. F. Chen, H. Yan, X. Wang, L. Xue, Mechanization technology and equipment for modern cotton production (Xinjiang Science and Technology Press, Xinjiang, 2008)

6. Y. Zhou, X. Liu, X. Yan, Mechanization of cotton harvesting (Xinjiang Science and Technology Press, Xinjiang, 2012)

7. L. Wang, H. Zhang, Q. Liu, T. China Soc. Agric. Eng. 32, 35 (2016)

8. X. Pei, B. Wang, X. Hu, L. Di, Y. Wang, C. Liu, NY/T 1133-2006 Operating quality for cotton picker (Ministry of Agriculture of the PRC, Beijing, 2006)
9. T. Li, F. Hao, Z. Han, X. Fang, C. Hao, Y. Liu, T. China Soc. Agric. Mach. 50, 63 (2019)

10. M. Huang, L. Shi, Y. Zhang, C. Chen, Y. Sun, Q. Xie, F. Kong, T. China Soc. Agric. Eng. 32, 21 (2016)

11. X. Ni, G. Xu, Q. Wang, X. Peng, J. Wang, B. Hu, T. China Soc. Agric. Mach. 48, 58 (2017)

12. Z. Xu, The optimal regression design of agricultural experiment (Heilongjiang Science and Technology Press, Harbin, 1998)

13. Y. Li, C. Hu, Experimental design and data processing (Chemical Industry Press, Beijing, 2008)

14. L. Shi, B. Sun, W. Zhao, X. Yang, S. Xin, J. Wang, T. China Soc. Agric. Mach. 50, 88 (2019)

15. F. Kahraman, Mater. Tech. 43, 267 (2009)

16. E. Mygdakos, T.A. Gemtos, Biosyst. Eng. 82, 381 (2002)

17. X. Sun, L. Shi, C. Chen, F. Kong, Y. Sun, J. China Agric. Mech. 39, 12 (2018)

18. X. Chen, J. Kang, T. China Soc. Agric. Mach. 43, 120 (2012)

19. Y. Ge, Experimental design method and DesignExpert software application (Harbin Institute of Technology Press, Harbin, 2014)

20. X. Xu, M. He, Experimental Design and Application of Design-Expert and SPSS (Science Press, Beijing, 2010) 